Article

\title{
Detecting Areas Vulnerable to Sand Encroachment Using Remote Sensing and GIS Techniques in Nouakchott, Mauritania
}

\author{
Diego Gómez *®D, Pablo Salvador ${ }^{\circledR}$, Julia Sanz, Carlos Casanova and Jose Luis Casanova \\ Remote Sensing Laboratory (LATUV), University of Valladolid, Paseo de Belen 11, 47011 Valladolid, Spain; \\ pablo@latuv.uva.es (P.S.); julia@latuv.uva.es (J.S.); casanovamateo@gmail.com (C.C.); jois@latuv.uva.es (J.L.C.) \\ * Correspondence: diego@latuv.uva.es
}

Received: 24 August 2018; Accepted: 21 September 2018; Published: 25 September 2018

\begin{abstract}
Sand dune advances poses a major threat to inhabitants and local authorities in the area of Nouakchott, Mauritania. Despite efforts to control dune mobility, accurate and adequate local studies are still needed to tackle sand encroachment. We have developed a Sand Dune Encroachment Vulnerability Index (SDEVI) to assess Nouakchott's vulnerability to sand dune encroachment. Said index is based on the geo-physical characteristics of the area (wind direction and intensity, slope and surface height, land use, vegetation or soil properties) with Geographic Information System (GIS) techniques that can support local authorities and decision-makers in implementing preventive measures or reducing impact on the population and urban infrastructures. In order to validate this new index, we use two remote sensing approaches: optical-Sentinel 2 and Synthetic Aperture Radar (SAR)-Sentinel 1 data. Results show that the greatest vulnerability is located in the north-eastern part of Nouakchott, where local conditions favor the advance of sand in the city, although medium to high values are also found in the eastern part. Optical images enabled us to distinguish desert sand using the ratio between near infrared/blue bands, and SAR Coherence Change Detection (CCD) imagery was used to assess the degree of stability of those sand bodies. The nature of the SDEVI index allows us to currently assess which areas are vulnerable to sand encroachment since we use long data records. Nevertheless, optical and SAR remote sensing allow sand evolution to be monitored on a near real-time basis.
\end{abstract}

Keywords: coherence change detection; GIS; preventive measures; sand encroachment; vulnerability

\section{Introduction}

Mauritania has been one of the countries most severely affected by repeated periods of drought that have occurred since 1960 [1]. The link between droughts and desertification in the Sahel region is clear [2]; hence desertification is a key issue in many North African countries [3]. According to the United Nations Convention to Combat Desertification (UNCCD), the term desertification refers to land degradation in arid, semi-arid and dry sub-humid areas resulting from various factors, including climatic variations and human activities [4]. Land degradation prompts problems such as poverty, food security and other socioeconomic miseries [5,6]. According to Pye et al. [7], aeolian sand deposits represent $6 \%$ of the total world land cover, with $97 \%$ of these deposits occurring in arid lands, which are prone to suffering problems related to desertification and sand encroachment $[3,8]$. In the near future, these events may be exacerbated by climate change, with severe disturbances not just in local temperatures but also in their hydrological cycles [9]. Less and increasingly erratic precipitation episodes will reduce water availability [10], thus conditioning crop yield [11] and sand dune mobility or stability [12]. When vegetation is not present, sand dune encroachment is a significant natural 
hazard that threatens cultivated lands, roads and urban infrastructures [13]. This natural challenge emerges from the disturbance of the fragile desert ecosystem, such that increased desertification will prompt sand encroachment [14]. There are various sand dune fixation techniques such as mechanical dune stabilization, protective screen, aerodynamic methods or biological fixation [1], yet vegetation (biological method) is the most common and most reliable stabilizer of loose sand [15]. The study area in the present work is Nouakchott (Mauritania), where several attempts have been made to protect the socioeconomic infrastructure of the city against sand encroachment [1]. The Nouakchott Green Belt was an initiative that started in 1975 to ensure the permanence, extension and sustainable management of the capital, although its effectiveness is currently limited due to erosion, lack of maintenance, animal grazing and the expansion of the city [16]. Therefore, more sand encroachment controls need to be implemented in order to protect Nouakchott's socio-economic infrastructure.

Some indices have been developed to evaluate sand transport in arid areas. However, they require long data records of climatic parameters and physical measurements, which are not always possible to achieve [17]. In addition, Lancaster et al. [17] suggest that validation methods are often difficult because field measures are short and not available on a multi-year basis. Some studies have focused on reducing the vulnerability of affected areas [18,19] and on monitoring the mobility of sand dunes [20]. In order to ensure the success of this type of project, satellite remote sensing approaches have been used to efficiently monitor large and difficult to access areas [21-23]. For instance, some works have mapped and classified dune forms [24], evaluated the evolution and spatiotemporal change of sand-dunes [25] or assessed sand dune advance [26]. In order to understand sand dune mobility in deserts, mobility indices have been developed using remote sensing or Geographic Information Systems (GIS) approaches. These mainly rely on two different components: the severity of the wind and the aridity of the region [27]. In an effort to reduce the vulnerability of sand encroachment, Effat et al. [13] developed a mapping approach based on GIS. Sand dune vulnerability maps are extremely convenient tools during the planning and designing phase of major desert development projects for tackling sand encroachment problems [28]. In addition, remote sensing techniques have also proven successful in sand dune movement studies [29].

In addition to the information provided by satellite platform optical sensors, radar remote sensing and interferometry have an enormous capacity to detect surface changes and desertification [22,30,31]. Synthetic Aperture Radar sensors (SAR) differ from optical sensors in the mechanism they use to detect electromagnetic energy [32]. These active platforms have the capacity to generate energy pulses towards the surface and to measure backscatter on the antenna, which may help to improve sand dune monitoring and vulnerability assessments. They provide images that are open to use in any weather conditions, such as under cloud coverage, and are capable of operating day or night [33,34]. They thus enable dynamic processes on the Earth's surface to be monitored in a reliable, continuous and global manner [35].

The aim of this study was to develop a vulnerability index to assess dune encroachment in Nouakchott (Mauritania) drawing on remote sensing data and GIS techniques. We also assess the capacity of the Interferometric SAR Coherence Change Detection (InSAR CCD) approach using Sentinel 1 (S1) images, as well as Sentinel 2 (S2) images to monitor sand dune stability.

\section{Study Area}

The study area covers $29,400 \mathrm{~km}^{2}$ and is located in Nouakchott (Figure 1). Despite efforts to control sand encroachment, the capital of Mauritania is still vulnerable to this sort of natural hazard [36]. Land cover is mostly bare ground, with some grassland over the southern part of the study area. Nouakchott is the largest urban settlement and RN1, RN2 and RN3 are the most important roads. Nouakchott International Airport is located $25 \mathrm{~km}$ to the north of the city. 


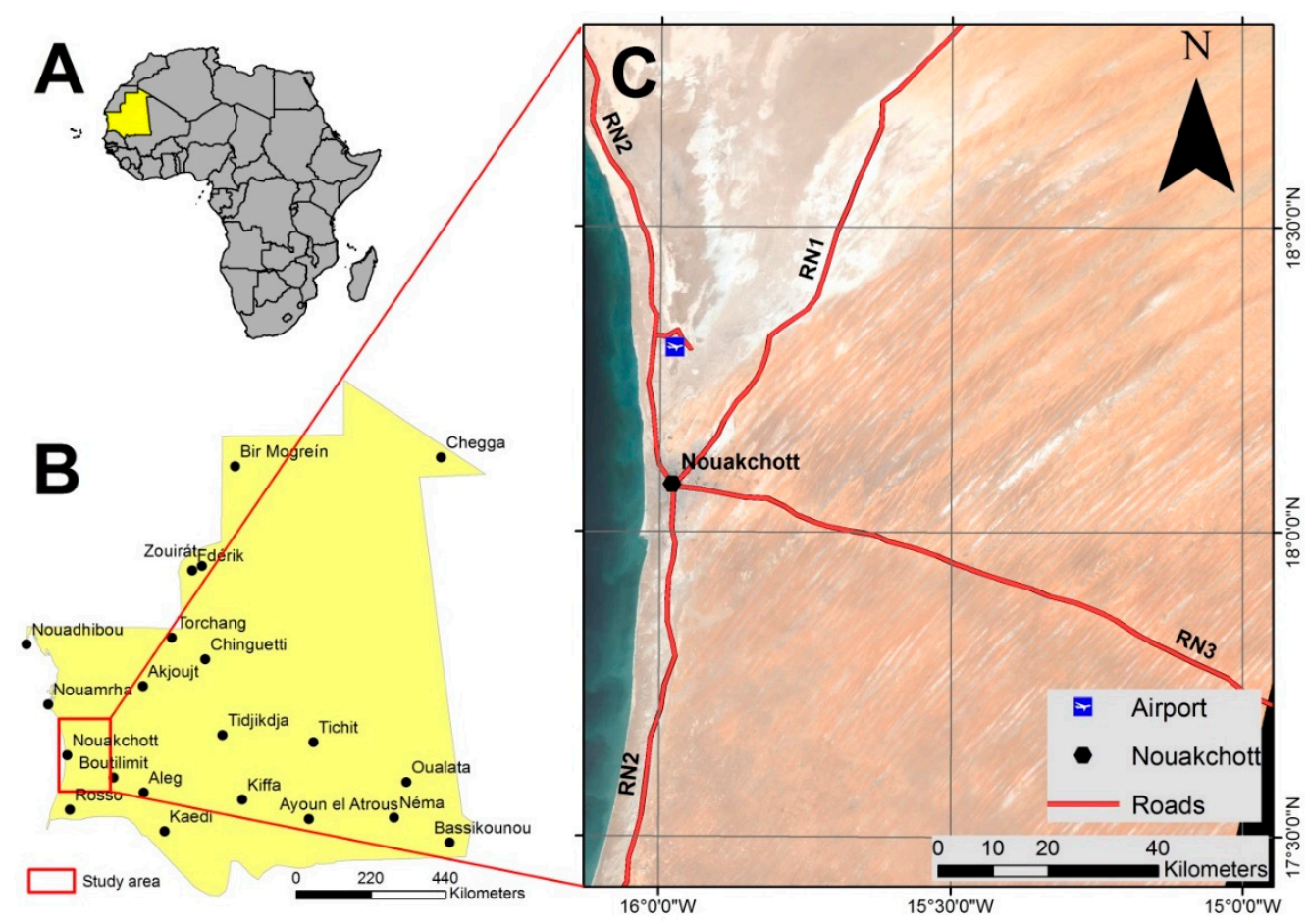

Figure 1. (A) Location of Mauritania within the African continent, (B) principal population sites and (C) location of the study area in Mauritania.

The climate is typically arid and hot, with seasonal variations in precipitation and temperature. From 2000 to 2015, the Nouakchott meteorological station reported annual average temperatures of $25.6{ }^{\circ} \mathrm{C}$ [37]. The warmest months are from June to October, with mean temperatures of over $27^{\circ} \mathrm{C}$, and January is the coolest with a $21.4^{\circ} \mathrm{C}$ average. The average of the maximum and minimum temperature records are $33^{\circ} \mathrm{C}$ and $20.6{ }^{\circ} \mathrm{C}$, respectively. Precipitation is concentrated in the summer months (July, August and September), and averages $120 \mathrm{~mm}$ per year. Wind is multidirectional, with predominant winds from the north-east from October to May, and from the north-west from June to September per season of the year [38]. Wind erosion creates longitudinal live dunes on sandy substrata $[39,40]$. These types of sand forms have an oscillating movement at their crests, and their bodies spread in accordance with wind patterns [41]. They can be up to ten times longer than they are wide. Furthermore, they are very common in arid environments with prevailing winds from two directions, or a single prevailing wind split by the morphology of the terrain [1].

Elevation ranges from 10 to $50 \mathrm{~m}$ in height, with an inactive sebkha (salt plain) in the northern part that lies $3 \mathrm{~m}$ below sea level. The dominant geology is made up of quaternary deposits, which are mainly dunes and sand cover. Marginal marine deposits along the coastline and to the north-east along with gypsum deposits in the north-west are the principal rock deposits [42]. Vegetation is quite scarce and sparse, with closed to open grasslands in the south of the study area, and a prevalence of bare soils in the northern part [43].

\section{Materials and Methodology}

\subsection{Vulnerability Analysis}

Previous studies have documented how sand encroachment and dune movements are greatly influenced by certain environmental factors such as wind speed, wind direction, sand availability or the morphology of sand dunes $[18,44]$. In this work, we used a derived approach of the Sand Dune Encroachment of Risk Index [13], modified to the singularities of our study area. We maintained factors such as elevation, slope, wind speed and direction. However, we also included other parameters that derive from geology, land cover/land use and remotely sensed soil moisture information. This new 
index is called the Sand Dune Encroachment Vulnerability Index (SDEVI), and aims to improve on previous efforts [18-20] carried out to assess vulnerability to the advance of sand as well as to help local authorities and decision-makers to devise predictive and mitigation measures. We considered adding remote sensing data in order to boost the adaptability of the assessment to our local conditions, as described in Equation (1). This index seeks to integrate the relevant and characteristic (physical and social) parameters that influence sand encroachment given the local conditions of the study area. It also provides a comprehensible value that comprises a number of interacting parameters, which represent diverse types of data. The SDEVI considers seven variables to indicate vulnerability to sand dune encroachment: speed factor (SpeFa), direction factor (DirFa), height factor (HeiFa), slope factor (SloFa), land use factor ( $\mathrm{LanFa}$ ), vegetation factor (VegFa) and soil cohesion factor (SoiFa). These variables were selected as they were thought to influence sand mobility in arid and semi-arid environments. Each variable is comprised of assigned scores that range from 1 (the lowest vulnerability) to 5 (the greatest vulnerability). Thus, we establish weights for each pixel/surface unit for each parameter in the study area. These parameters are included in Equation (1) to provide a vulnerability score (Table 1). The ranking component is adjusted depending on the environmental factors of the area as observed in previous vulnerability assessments $[13,45]$. We employ map algebra in a GIS software (ESRI 2016. ArcMap 10.4. Redlands, CA, USA: Environmental Systems Research Institute) following Equation (1). Note that all the parameters have been resampled to the finest possible resolution, the land cover map (European Space Agency Climate Change Initiative-ESA CCI-Land Cover of Africa 2016), with $20 \mathrm{~m} \times 20 \mathrm{~m}$ per pixel, using the nearest neighbour technique.

$$
\mathrm{SDEVI}=\mathrm{SpeFa}+\mathrm{DirFa}+\mathrm{HeiFa}+\mathrm{SloFa}+\mathrm{LanFa}+\mathrm{VegFa}+\mathrm{SoiFa}
$$

where: SpeFa (Speed Factor), DirFa (Direction Factor), HeiFa (Height Factor), SloFa (Slope Factor), LanFa (Land Factor), VegFa (Vegetation Factor) and SoiFa (Soil Factor).

Table 1. Sand dune encroachment vulnerability according to the Sand Dune Encroachment Vulnerability Index (SDEVI) index.

\begin{tabular}{ccc}
\hline Score & Ranking of Vulnerability & SDEVI Vulnerability Index \\
\hline $\mathbf{1}$ & Very low & $<12$ \\
$\mathbf{2}$ & Low & 12 to 17 \\
$\mathbf{3}$ & Medium & 17 to 22 \\
$\mathbf{4}$ & High & 22 to 27 \\
$\mathbf{5}$ & Very high & $>27$ \\
\hline
\end{tabular}

The SpeFa provides information about the capacity of the winds to erode and transport sand deposits. This factor, along with the direction factor, is related to the sand sheet formation and shape of the dunes [18]. Wind speed data were derived from the GLDAS Model (GLDAS_NOAH025_M v2.0) using the Giovanni platform from GSCF NASA (https:/ / giovanni.gsfc.nasa.gov/giovanni/). This platform generated a time averaged map of near surface wind speed in $\mathrm{m} / \mathrm{s}$ units from 2000 to 2010 , with a spatial resolution of $0.25^{\circ}$. We reclassified speed values by dividing them into equal intervals using the minimum and maximum wind speed values observed in the study area: $0-2 \mathrm{~m} / \mathrm{s}$ (1), $2-3.5 \mathrm{~m} / \mathrm{s}$ (2), 3.5 to $4.5 \mathrm{~m} / \mathrm{s}$ (3), 4.5 to $5.5 \mathrm{~m} / \mathrm{s}$ (4) and $>5.5 \mathrm{~m} / \mathrm{s}$ (5) (Figure 2).

The DirFa indicates the type of sand dunes and their alignment due to it being greatly conditioned by the prevailing wind direction [26]. This factor was derived from meteorological data from the Modern-Era Retrospective analysis for Research and Applications (MERRA) dataset (Figure 3). The MATMCPUDT (MERRA 3D IAU Tendency, Wind Components, and Monthly Mean V5.2.) product has a one-month temporal resolution and a $1.25^{\circ}$ spatial resolution [46]. As in SpeFa, we used the Giovanni platform to generate a map of wind direction tendency. We obtained the average of the wind direction from 1947 to 2015 , which is expressed in degrees from $0^{\circ}$ to $360^{\circ}$, where $0^{\circ}$ points 
to the north and the degrees increase clockwise. Thus, when the wind has a southerly direction it corresponds to $180^{\circ}$.
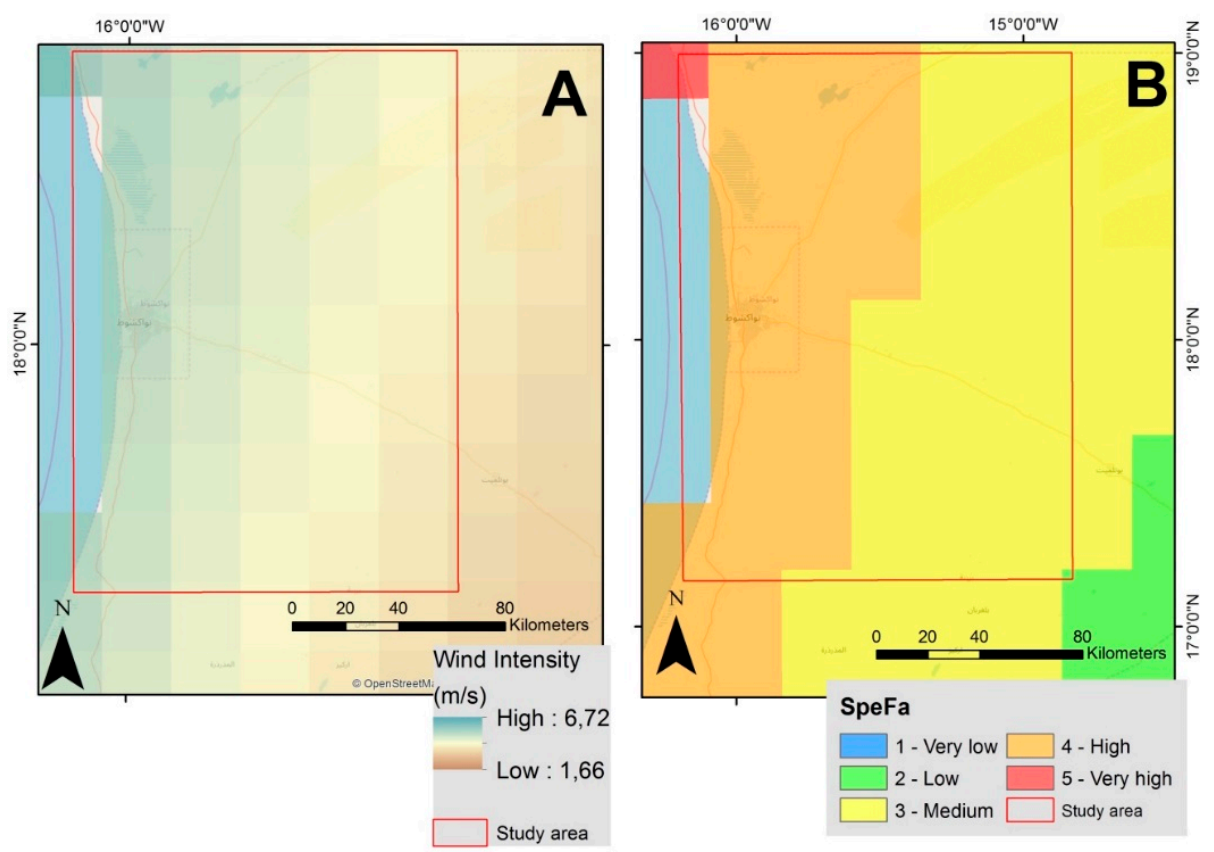

Figure 2. (A) Wind intensity map and (B) Speed Factor (SpeFa) vulnerability map.

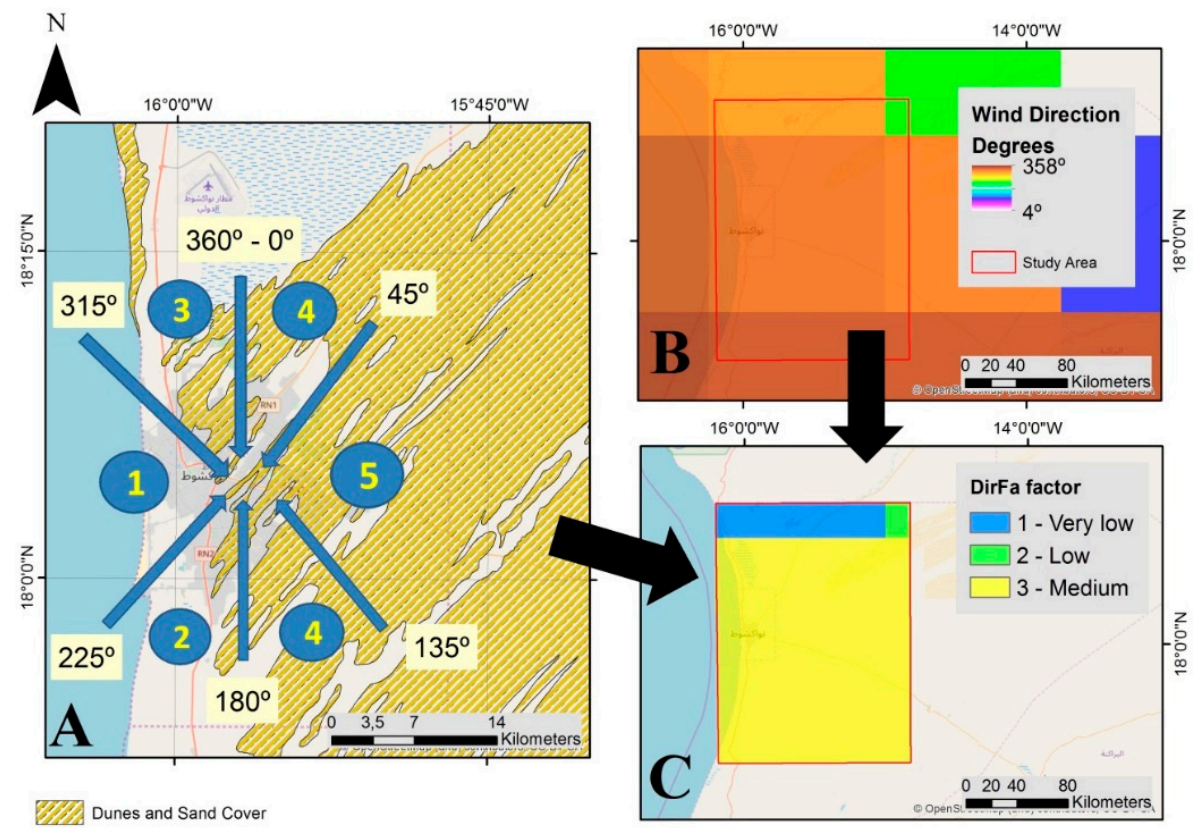

Figure 3. (A) Vulnerability of Nouakchott if the wind blows from each of the angle ranges displayed in the graph. The numbers represent the assigned vulnerability level in accordance with the sand dune map, (B) wind direction map of the study area and $(\mathbf{C})$ vulnerability map according to the wind direction factor.

In order to classify the zonal vulnerability for this factor, we weighted which directions would be more relevant in terms of sand mobility. The geological map [42] shows some sand dune areas that may present enough sand to be mobilized if proper wind conditions are met. We reclassified the wind direction as follows: 225 to $315^{\circ}$ (1), from 180 to $225^{\circ}$ (2); 315 to $360^{\circ}$ (3); 0 to $45^{\circ}$ (4) and 135 to $180^{\circ}$ (4) and 45 to $135^{\circ}(5)$. 
The HeiFa was extracted from the Digital Elevation Model (DEM) generated by the Shuttle Radar Topography Mission SRTM (NASA, JPL, Pasadena, CA, USA) with a $30 \mathrm{~m}$ spatial resolution (https:/ /www2.jpl.nasa.gov/srtm/) [47]. Previous studies have shown the relation between sand movement rate and dune height $[48,49]$, although this can also be affected by the maturity of the dunes [50]. As described in Effat et al. [13], higher elevation areas are more subject to sand dune activity. We reclassified the height map (Figure 4) in order to generate the HeiFa using natural breaks, rounded up to the nearest $10(<10 \mathrm{~m} .=1 ; 10-20 \mathrm{~m} .=2 ; 20-40=3 ; 40-60=4 ;>60=5)$.
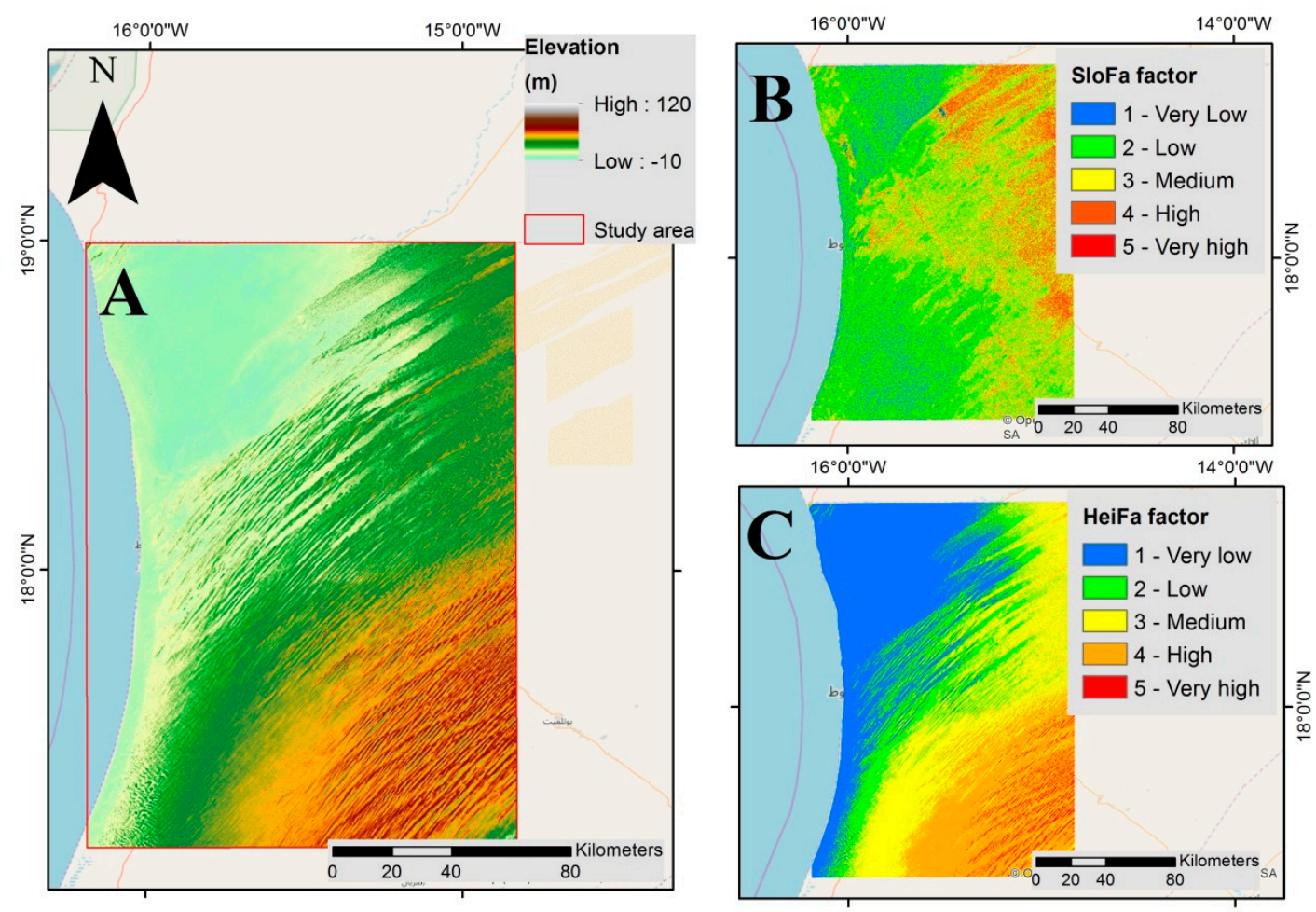

Figure 4. (A) Elevation map, (B) slope factor (SloFa) and (C) height factor (HeiFa).

The SloFa offers valuable information about sand advances: hence different degrees of vulnerability are also associated (Figure 5). High slope angles are thus related to greater vulnerability [51] and these were reclassified accordingly $(0-2 \%=1 ; 2-5 \%=2 ; 5-10 \%=3 ; 10-15 \%=4$; $>15 \%=5)$.

The LanFa is difficult to determine since detailed and actual land cover information is not usually available [52]. Nevertheless, recent release of the ESA CCI Land Cover of Africa 2016 offers a major source of information for inclusion in our vulnerability analysis (http://2016africalandcover20m. esrin.esa.int/). We reclassified each unit in accordance with its vulnerability to sand encroachment in Figure 5 (bare areas $=1$; vegetation from dense to sparse $=2$; rivers and channels $=3$; roads and crops $=4$ and urban infrastructures: dwellings, airport, etc. $=5$ ). These scores are based on the impact that sand encroachment would have on social and economic interests.

The VegFa is a very important factor to assess vulnerability. Sand dunes can be mobile, semi-mobile or fixed depending on several factors, the most important of which are vegetation or wind [53]. This is a difficult to monitor factor since vegetation cover changes with climatic parameters such as precipitation and affects the amount of sand available for transportation. Nevertheless, we reclassified the ESA CCI Land Cover of Africa 2016 map according to the density of the vegetation units (Figure 5). Trees and open water were given a (1) value; grassland and cropland (2); aquatic or regularly flooded vegetation (3); sparse vegetation or shrub-covered land (4), and bare soil and urban areas (5). 

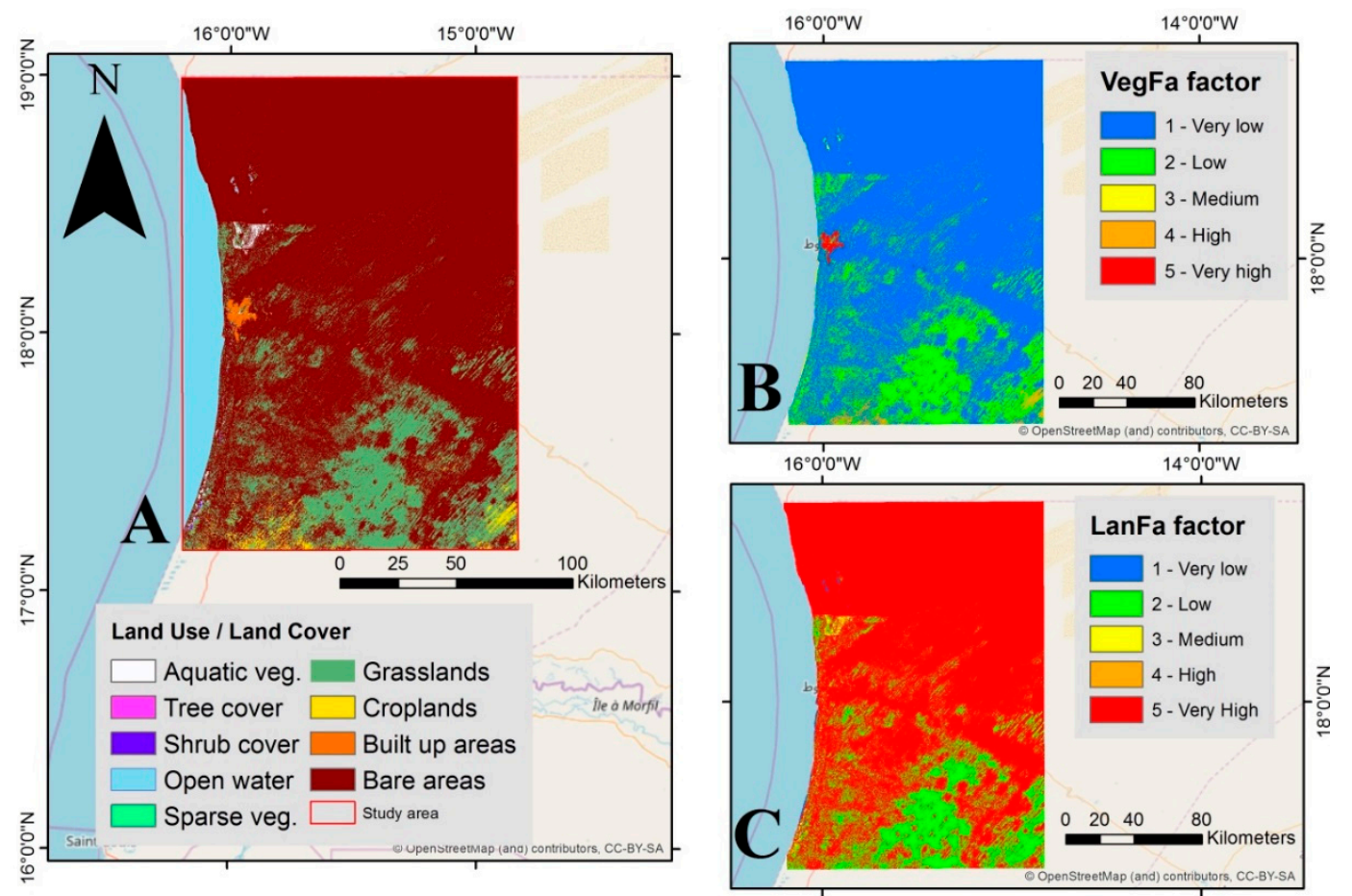

Figure 5. (A) Land Use/Land Cover map, (B) vegetation factor (VegFa) and (C) land factor (LanFa). Source: ESA CCI Land Cover of Africa 2016.

The SoiFa was generated based on two parameters: soil moisture and lithology. Soil moisture is an extremely important parameter in monitoring sand movement in arid regions [54]. We used a soil moisture product generated via the Climate Change Initiative (CCI) of the European Space Agency (ESA, Paris, France) ESA CCI SM v03.2. This is a merged product from radar and radiometer sensors of the volumetric surface (volume of water within $1 \mathrm{~m}^{3}$ of soil) up to $5 \mathrm{~cm}$ in depth and expressed in $\mathrm{m}^{3} / \mathrm{m}^{3}$ units (https:/ / www.esa-soilmoisture-cci.org/). Its spatial resolution is $0.25^{\circ}$ and it offers worldwide daily coverage from 1978 up to 2015 [55-57]. We computed a soil moisture average from 1978 to 2015 over the study area. According to some literature, a fully dry soil ranges from 0.0 to $0.05 \mathrm{~m}^{3} / \mathrm{m}^{3}$, while a completely wet one would have values up to $0.5 \mathrm{~m}^{3} / \mathrm{m}^{3}$ [58]. Based on these values, we reclassified soil moisture values as follows: 0.0 to $0.05 \mathrm{~m}^{3} / \mathrm{m}^{3}$ (5), 0.05 to $0.1 \mathrm{~m}^{3} / \mathrm{m}^{3}$ (4), 0.1 to $0.2 \mathrm{~m}^{3} / \mathrm{m}^{3}$ (3), 0.2 to $0.4 \mathrm{~m}^{3} / \mathrm{m}^{3}$ (2) and 0.4 to $0.5 \mathrm{~m}^{3} / \mathrm{m}^{3}$ (1).

Based on the lithological information provided by Geology IRM [42], we reclassified each geological unit in accordance with its consolidation and resistance to mobility. Thus, we assigned the highest value (5) to dunes and sand cover, which are mainly non-consolidated units. Sand over desert pavement was assigned a (4) and fluvial deposits and alluvium formations a (3). Marine and marginal marine deposits, inactive sebkhas (gypsum), sandstones, clayey sands and iron pans were assigned a (2). The most consolidated formations are calcrete and silcrete (hamadas), which were assigned a (1).

We computed the average of each pixel with a $500 \mathrm{~m}$ resolution between soil moisture and lithology parameters to generate the soil cohesion factor (Figure 6). 


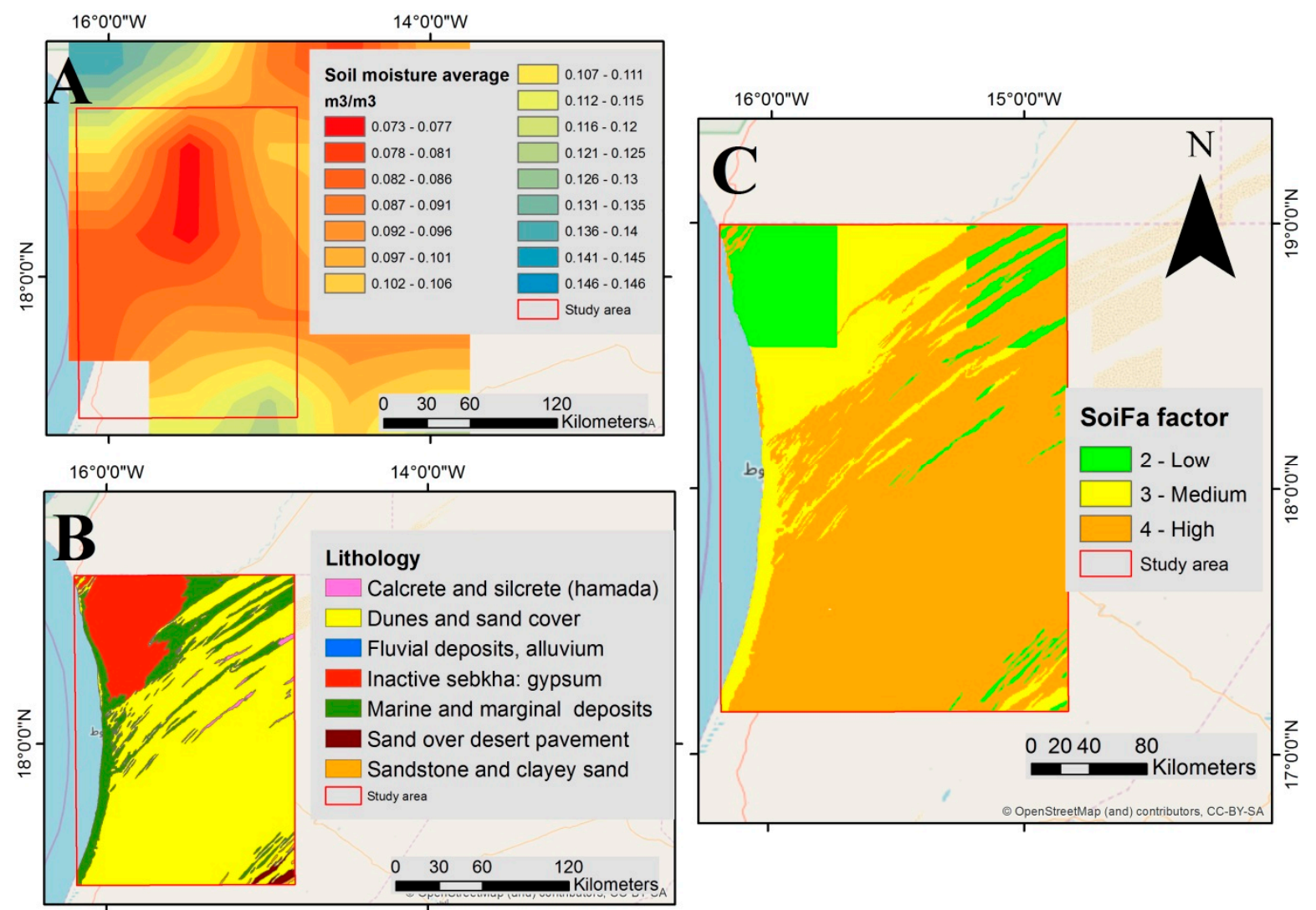

Figure 6. (A) Average soil moisture map, (B) lithological map and (C) soil factor map (SoiFa).

\subsection{Remote Sensing Data}

In order to validate the index proposed in this work, we used two different remote sensing approaches based on visual comparison. The first involves optical images from the Sentinel 2-A (S2A) and Sentinel 2-B (S2B) satellites of the ESA. The Sentinel Satellites were developed for the specific needs of the Copernicus Programme. Copernicus is the European Union's Earth Observation Programme. They are twin polar orbiting satellites in the same orbit that provide a revisit time of five days. They carry a Multi-Spectral Instrument which has 13 spectral bands: four bands at $10 \mathrm{~m}$, six bands at $20 \mathrm{~m}$ and three bands at $60 \mathrm{~m}$ spatial resolution [59].

We downloaded 16 Sentinel 2 cloud free images (four per date) throughout 2017, aiming to capture dune changes in the study area. These images were acquired on the following dates: 7 February 2017 (S2A), 18 April 2017 (S2A), 7 July 2017 (S2A), and 17 October 2017 (S2B). Images were atmospherically corrected using the SEN2COR algorithm implemented in the SNAP Sentinel Application Platform toolbox [60] from Top of Atmosphere (TOA) reflectance to Bottom of Atmosphere (BOA) reflectance [61]. We then merged the four images corresponding to each date into a mosaic so as to cover the whole study area. The new mosaic was subset to the study area, exporting bands 2 (B), 3 (Green), 4 (Red) and 8 (Near Infrared) at $10 \mathrm{~m}$ resolution to generate RGB and false color composite images. Previous approaches have traditionally relied on natural color images to monitor aeolian sand dunes [62,63]. However, there are other alternatives for optical sensors such as the analysis of false color composite images shown in Ahmady-Birgani et al. [18]. Based on the reflectance properties of desert sand [64,65], we selected band 2 and band 8 to retrieve low and high sand reflectance, respectively. A false color composite image was then generated in order to better distinguish desert sand. The B8/B2 ratio was used for the red channel, band 8 for the green channel, and band 2 for the blue channel. This combination affords a better discrimination of active sand formations compared to natural color composites. We have not observed any similar band composition in previous studies addressing sand encroachment issues. This ratio relies on the spectral properties of desert sand, which reflects highly in the near infrared 
region; while reflectance on the blue part of the spectrum is comparatively lower [66]. The images corresponding to each date were visually compared against the other dates for RGB and false color composites in order to analyze sand advance.

The second approach is the SAR interferometric coherence change detection (CCD). This technique has already been successfully applied to study aeolian morphodynamics in order to monitor surface changes $[22,67,68]$. The CCD approach combines two SAR images of the same area taken at different times to detect changes on the surface $[69,70]$. In arid environments, changes in sand dunes are controlled by erosion/deposition processes and sediment transport, which also affects the backscatter retrieved by the sensor [30]. We downloaded four Sentinel 1 images in Single Look Complex format in Vertical-Vertical polarization acquired in Interferometric Wide mode. Their dates (7 February 2017; 20 April 2017; 13 July 2017 and 17 October 2017) were chosen to match the optical images from S2. The S1 images were processed following Veci [71] with SNAP software from the ESA [72]. First, we applied S1 Tops Coregistration to obtain a stacked image pair. The image corresponding to the first acquisition date (7 February 2017) was selected as the master, while the rest of the acquisitions were subsequently selected as slaves. This method ensures that each pixel in both images (master and slave) is aligned and represents the same ground targets. The next step was interferogram formation with three different outputs: amplitude, phase (phase difference between two images) and coherence (similarity of each pixel between slave and master image). The TOPS Deburst tool was used to merge all the bursts into a single image. Images were geometrically corrected using Range Doppler Terrain Correction [73] so as to have the correct orientation and be geo-rectified. We only used the coherence information of each pair of images [22]. Values range from 0 (lowest coherence) to 1 (highest coherence). Physical changes or movement of scatters may decrease coherence. As a result, agricultural fields or forests usually present low values in comparison to urban or non-vegetated areas [74]. Coherence between two images is estimated using the coherence equation proposed in Gaber et al. and Liu et al. [30,75]. The coherence images were then classified into change and no-change areas based on the coherence maps. We analyzed the histograms of the three coherence images and they were visually compared with the optical images from S2. It was thus found that $>0.6$ coherence values would represent "no change", while lower values would account for surface changes.

\section{Results}

The spatial vulnerability of each pixel $(20 \times 20 \mathrm{~m}$ resolution $)$ is presented in Figure 7 , showing three different degrees: low, medium and high. The lowest vulnerability is observed in the northern part with values between 15 and 18. Medium values are predominant over the study area, ranging from 19 to 22 . The highest values are located in the eastern part, and range from 23 to 30. The international airport of Nouakchott-Oumtounsy is located $25 \mathrm{~km}$ north of Nouakchott and presents low vulnerability to dune encroachment. The three main national roads are: RN1 (Nouakchott-Atar-Zoueratte-Algeria border), RN2 (Nouadhibou-Nouakchott-Rosso-Senegal border) and RN3 (Nouakchott-Kiffa-Nema-Mali border). According to the SDEVI index for the study area, RN3 is highly vulnerable to sand encroachment while RN1 and RN2 lie on medium to low areas. The RN3 road connects Nouakchott to important cities in the south of Mauritania such as Boutilimit, Nema or Kiffa. Given the high susceptibility of this road to sand encroachment, it runs the risk of being cut off and of seeing traffic between the capital and other towns in central and southern Mauritania interrupted.

In Nouakchott, the most vulnerable area is the eastern and northern part of the city, with vulnerability values ranging from medium to high (23 to 27) (Figure 7, bottom-right). The center and south of the city evidence lower vulnerability, with values from medium to low (17-22). It should be noted that a small area in the western part of Nouakchott is missing due to a lack of information for some of the factors, such that it was not possible to calculate the SDEVI. 


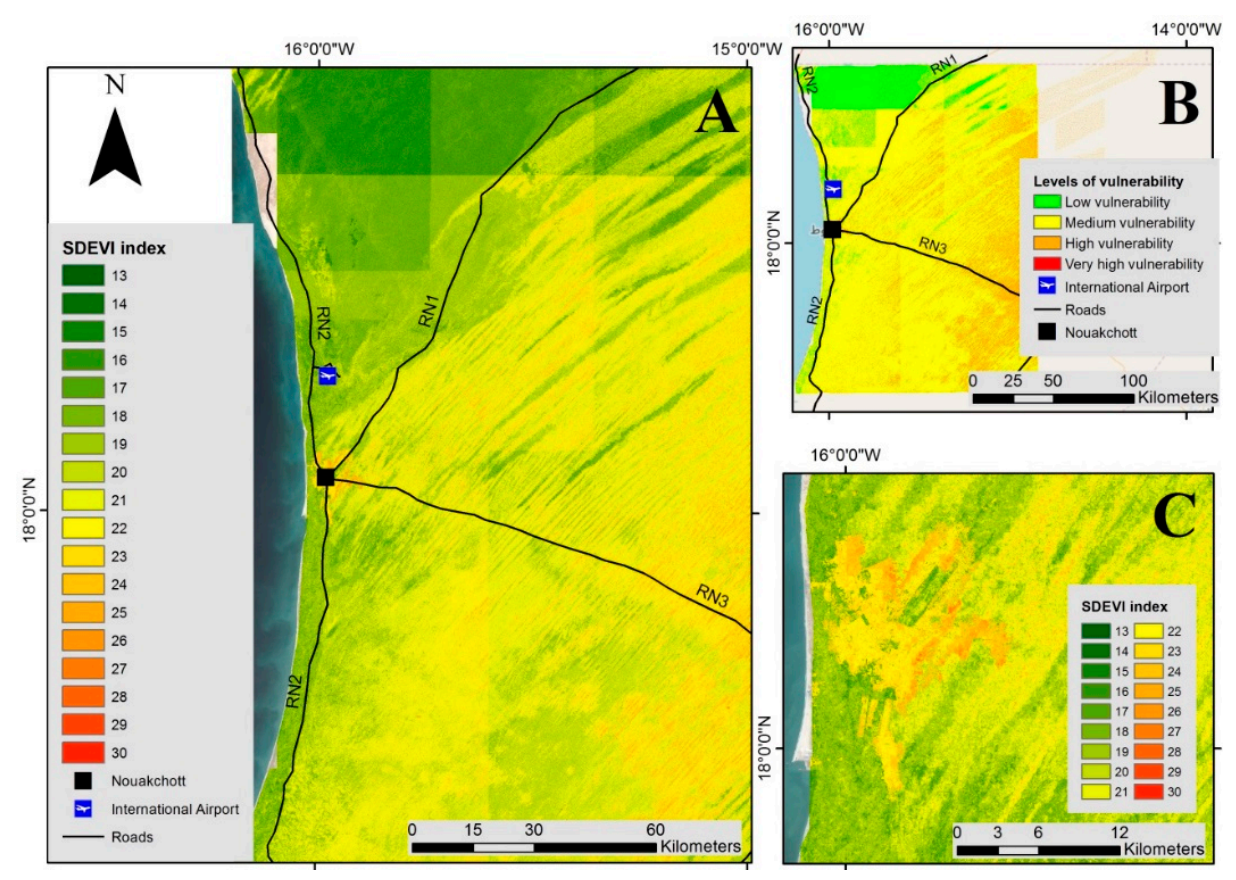

Figure 7. (A) Map of the SDEVI index to assess vulnerability to sand dune encroachment over the study area, (B) Levels of vulnerability according to Table 1 and (C) vulnerability map over Nouakchott city (bottom-right). Open street map is the basemap in the images.

Figure 8 shows temporal sand changes using optical images from S2. Three different types of images have been generated: natural color composites (B4-B3-B2), false color composites (B8/B2-B8-B2) and the B8/B2 ratio. We observed that natural color images provide a reasonable visual approach to differentiate desert sand dunes within the study area (left column). The selected false color composites enhance sand reflectance (yellow) over urban areas (grey and black) or soil materials other than shifting desert sand (white).

The B8/B2 ratio has been shown to be a very good proxy to identify sand dune formations, being able to clearly distinguish sand dunes from other materials. Given the different reflectance of desert sand in the infrared and blue part of the spectrum, their ratio emerges as a good indicator or classifier. Based on this knowledge, we analyzed the histograms of the four ratio images (right column) and reclassified the images using the quantile classification method available in GIS software. We adjusted the threshold to suit desert sand distribution, and this was found to be 2.51. Values below this threshold were considered to be not covered by desert sand. In Figure 9, we present the differences in sand cover at Nouakchott from the first image (February) compared to the rest (April, July and October) using the ratio approach.

The ratio obtained for the February acquisition was taken as a reference (yellow). The ratio of the rest of the dates were then overlaid (red). A slight sand dune advance heading south-east for the first comparison is evident (7 February and 18 April), although fewer changes can be seen. The second comparison (7 February and 7 July) indicates more changes concerning sand dune locations. The previously observed covered area in April has shrunk, with noticeable changes in the south-east and northern part of Nouakchott. Even though an increase in dune extension on 20 October 2017 can be seen, the relative cover area is lower than the reference image. The zoomed image (Figure 9, top-right) shows the advance of dunes in a south-east direction as occurred in the first zoomed image. This highlights the vulnerability of the north of Nouakchott to sand encroachment. 

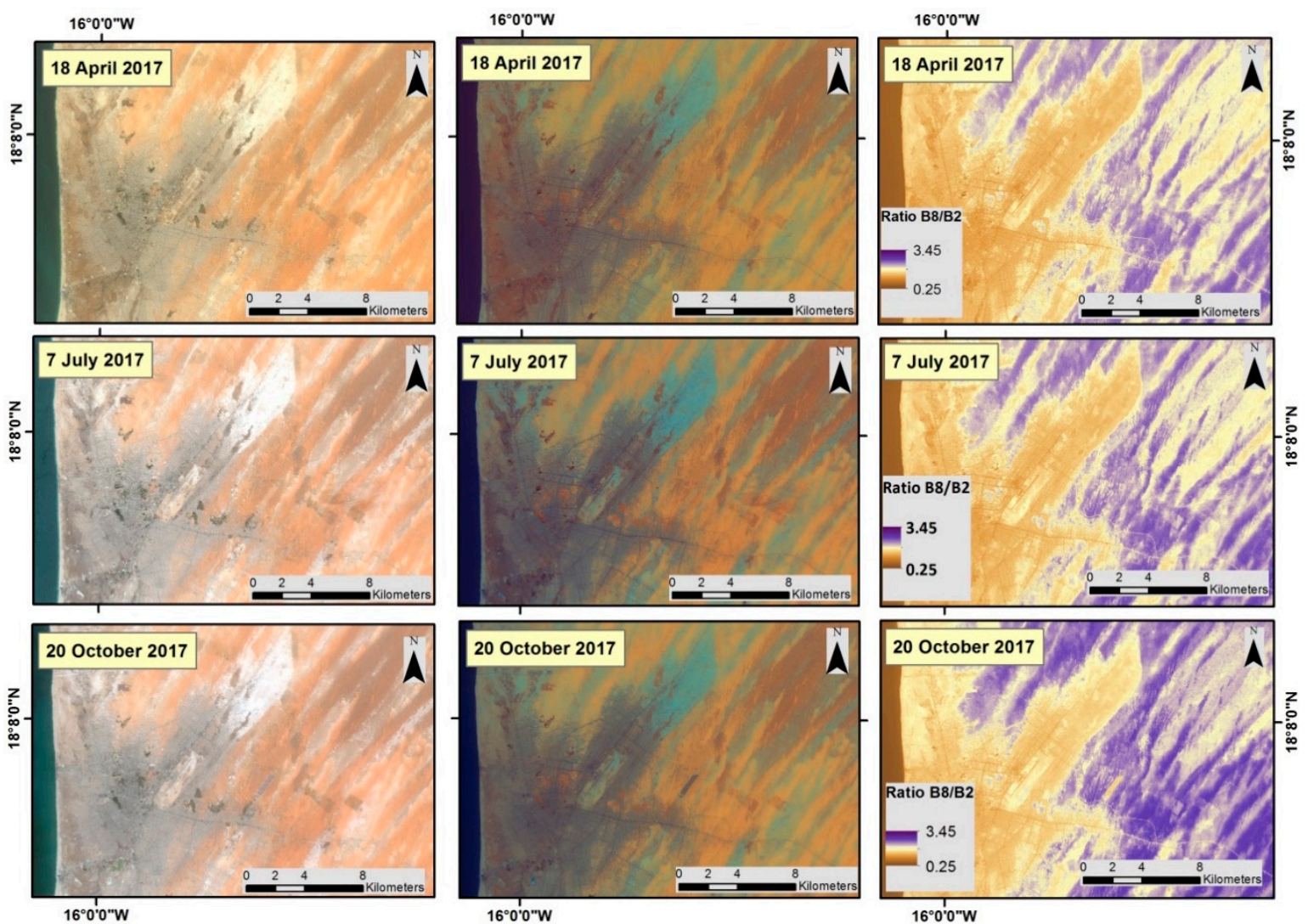

Figure 8. Natural color composite (left), false composite color (center) and B8/B2 ratio (right) images at Nouakchott to assess sand mobility.

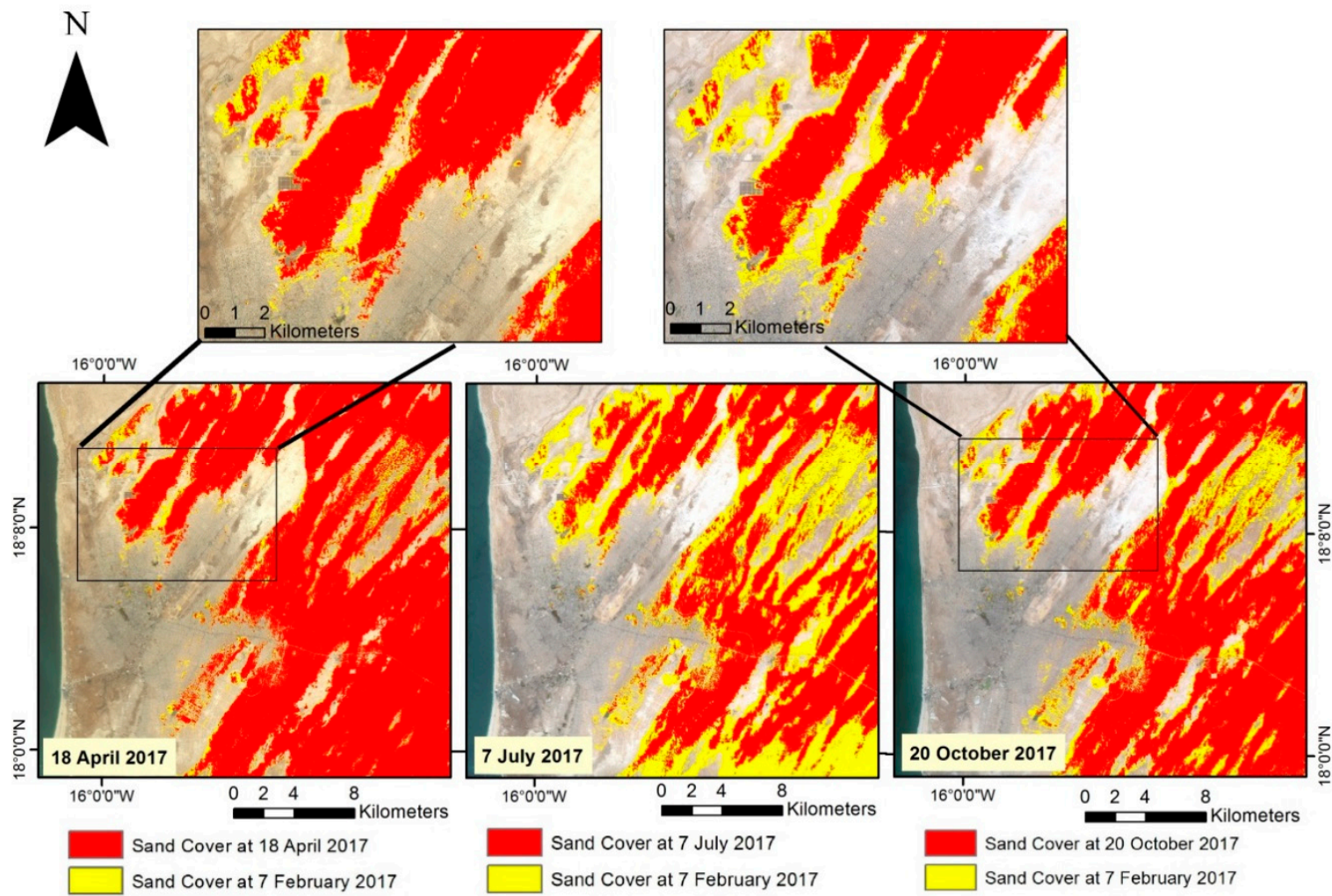

Figure 9. Sand dune changes during 2017 taking the image from 7 February 2017 (yellow) as a reference. 
We also used SAR data to validate the vulnerability assessment of our methodology. The CCD technique was used to measure changes in backscatter amplitude for three pairs of images acquired over the same area. The master image corresponds to the February SAR acquisition, and slave images in April, July and October. As a result, we obtained coherence maps that provide information about surface changes (Figure 10). These maps indicate the high coherence (bright pixels) over the urban land of Nouakchott.

The general morphological features of the sand bodies concur with the patterns observed in Sentinel 2 images, although it should be noted that S1 has lower spatial resolution (20 $\mathrm{m})$ and is therefore not as geometrically precise (Figure 11). It was found that those areas with coherence values greater than 0.6 represent stable areas such as buildings, paved roads or bare ground, whereas lower values indicate backscatter changes, which may reflect unstable sand formations. The high coherence values observed in the city (up to 1) indicate its stability. Nevertheless, lower values are also present and explain variations in buildings, vegetation or soil moisture of urban surfaces. When comparing Sentinel 1 CCD values $(C C D>0.6)$ and the Sentinel 2 ratio (B8/B2 > 2.51) as observed in Figure 10 (C1, $\mathrm{C} 2$ and $\mathrm{C} 3$ ), similar sand patterns are found in most of the study area. Some discrepancies are evident to the west, where vegetation is more abundant (Figure 8, natural color composites) and may lead to losses in coherence. However, non-vegetated areas show similar patterns in sand distribution between Sentinel 1 and Sentinel 2 data.

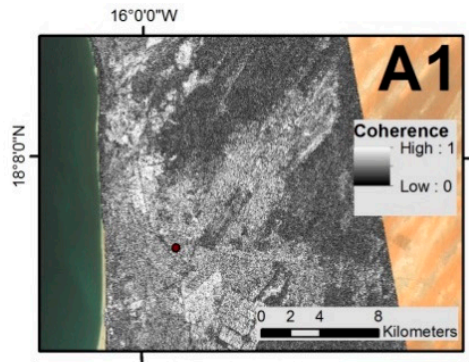

$16^{\circ} 0^{\circ} 0^{\circ} \mathrm{W}$
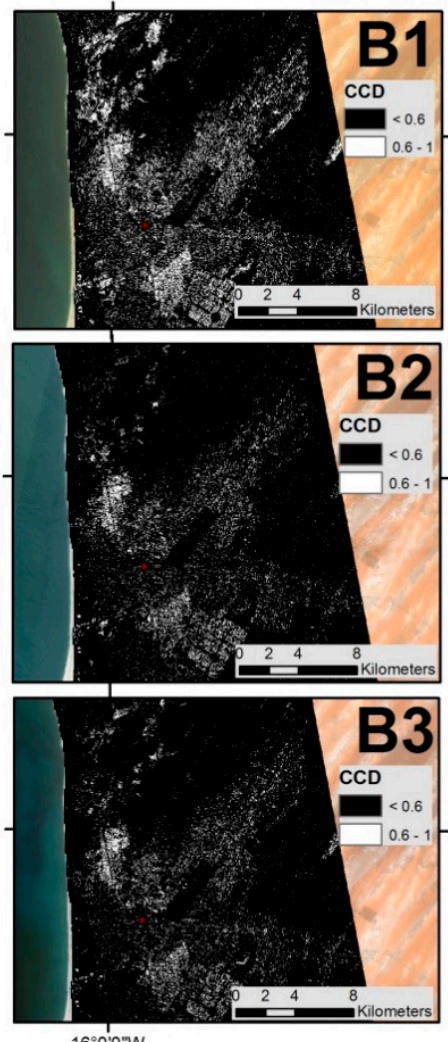

$16^{\circ} 0^{\circ} 0^{\prime \prime W}$
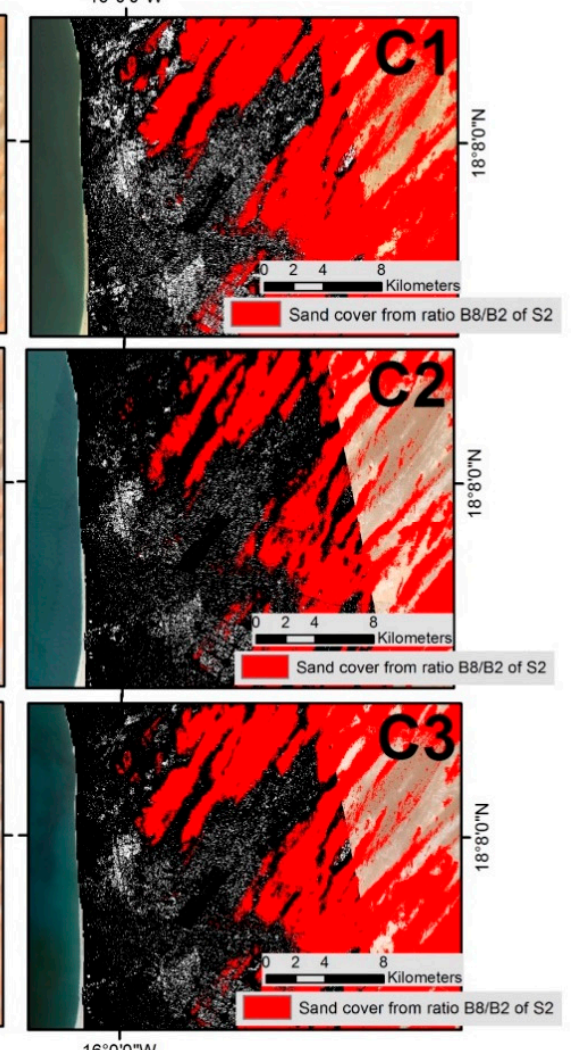
$16^{\circ} 0^{\circ} 0 \mathrm{WW}$

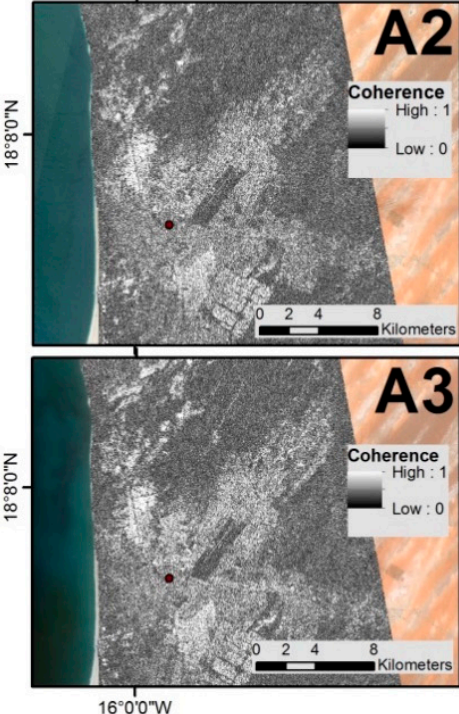

$16^{\circ} 0^{\circ} 0^{\circ} \mathrm{W}$

Figure 10. (A) Coherence images corresponding to the following image pairs: master (7 February 2017) and, respectively, slaves: 20 April 2017 (1), 13 July 2017 (2) and 17 October 2017 (3). (B) Coherence Change Detection (CCD) images with the 0.6 threshold and then the output of the B8/B2 ratio from Sentinel 2 images overlaid (C). 


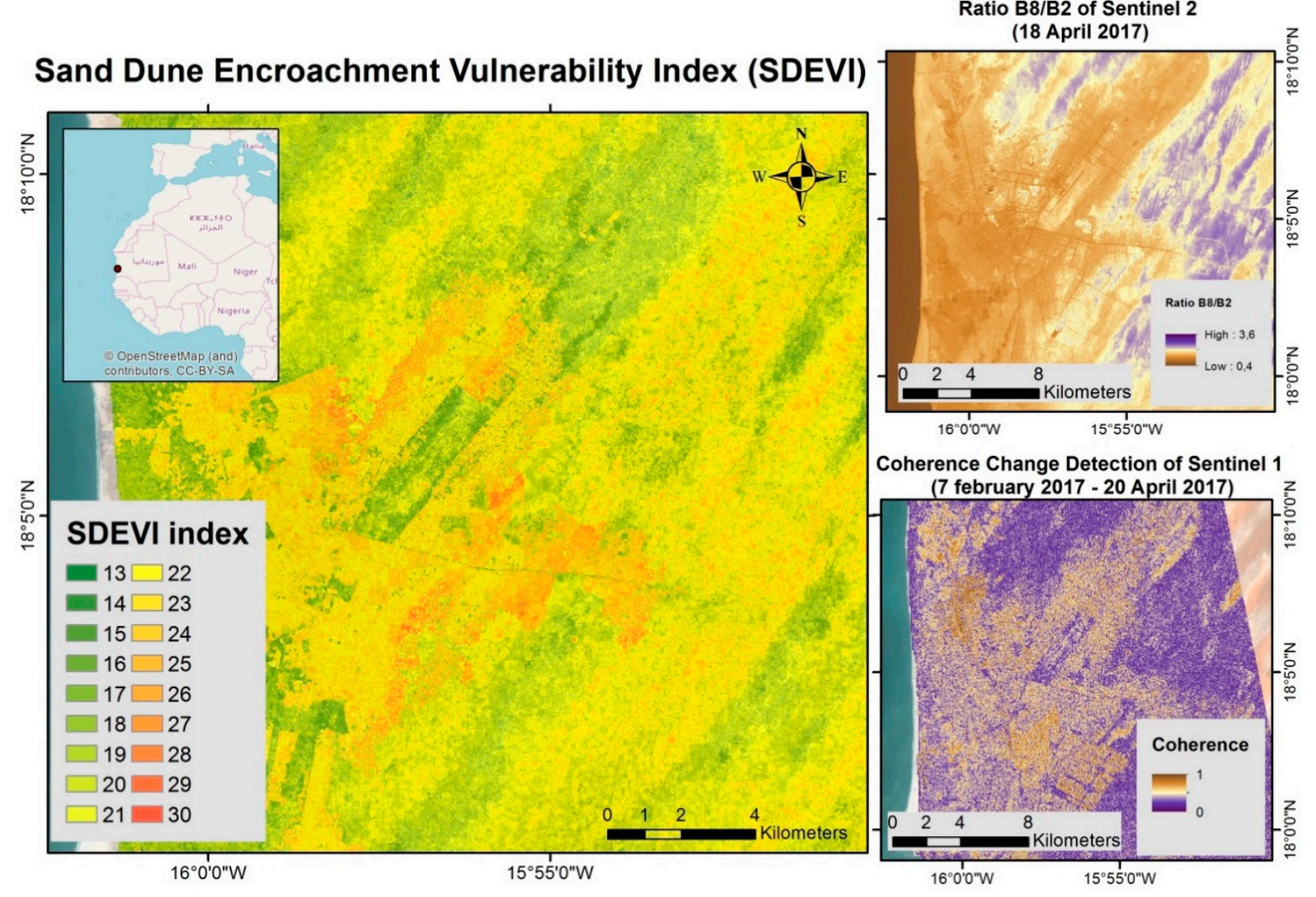

Figure 11. SDEVI map, ratio B8/B2 image of Sentinel 2 from 18 April 2017, and Coherence image from 7 February 2017-20 February 2017.

\section{Discussion}

In an effort to assess the degree of vulnerability as well as to improve the land management of certain arid areas, we suggest using the SDEVI. This index's vulnerability values offer high resolution information about vulnerability to sand encroachment. Previous efforts have evaluated similar issues in arid environments using vulnerability indices [13], although some limitations such as missing data or coarse resolutions have been encountered. New satellite platforms seek to overcome these problems by using high spatial and temporal resolution for remote and inaccessible areas [76]. The SDEVI results (Figure 7) are in accordance with previous efforts observed in the area, where the implementation of preventive measures has been observed [77]. The highest vulnerability values (north-east of Nouakchott) geographically coincides with the in-situ initiative called the "Nouakchott Green Belt" project, which sought to protect the city against sand encroachments. Nevertheless, our methodology includes other means to validate the approach presented in this work and offers high resolution imagery for land use planning and environmental management. The S1 and S2 satellites offer valuable information to monitor environments and establish protocols against natural hazards [78], such that they were found to be appropriate for gauging the performance of our vulnerability index.

Using optical S2 bands, we generated three different types of raster images (Figure 8): natural color (Red, Green and Blue) composite images, false color composite images (NIR, Red and Blue) and the ratio (NIR/Blue). Previous efforts have explored the benefits of studying the spectral properties of soil in the NIR region, being able to predict certain features such as sand content [79]. We visually compare ratio images with their corresponding RGB composite images. The histogram analysis of the ratio images was adjusted to separate the sand dune morphologies observed in the RGB images. This procedure enabled us to establish the threshold at 2.51 (pixel values $>2.51$, unstable sand dune formations) (Figure 9). These results are in accordance with visual interpretations of natural and false composite images, identifying sand dune formations with high vulnerability in the north and north-east of Nouakchott. In addition, the ratio procedure reduces the complexity of image generation 
(with only two bands) and classification (establishing a one-layer image with a threshold). To the best of our knowledge, no previous efforts have used this ratio procedure to identify desert sand dunes, and it may not only be used for validation purposes as detailed in this work, but also as a stand-alone monitoring technique for the mobility and advance of sand dunes in the study area.

The information provided by the S1 satellite was also used to validate the SDEVI. Unlike the optical part of the electromagnetic spectrum obtained by S2, images from S1 SAR offer information on surface inclination, roughness, and the dielectric constant of the target material [80]. CCD images show similar sand dune identification (Figure 10) when compared to optical methods, with only a few differences being observed in the eastern and southern part of Nouakchott. In that area, the SDEVI index presents the lowest values over Nouakchott and the surrounding area. As SAR coherence enhances changes in backscatter between two different acquisitions in terms of date, low coherence values may be accounted for by vegetation growth or changes in land use [81]. Pixels with a $<0.6$ temporal coherence were considered unstable. This threshold was found by analyzing the histograms of the three coherence images and using the optical images as a reference. This result concurs with other studies that highlight the 0.6 threshold as an acceptable value to assess land cover changes [82]. We obtained values close to one for urban areas as found in [83], whereas sand dune coherence presents values $<0.6$ as observed in Havivi et al. [67]. Although the SAR coherence technique enables sand dune advances to be described in space and time, this author underlines the problem of interpreting these images due to the influence of wind and rainfall on the phase signal, which is sensitive to subtle changes in ambient conditions. Thus, we agree with Blumberg et al. [84] that SAR data holds a potential value to map morphologies and geological structures. Nevertheless, we also believe that, if combined with SAR data, optical methods may ensure a more practical interpretation of the results.

We found similarities between S1 and S2 images to discriminate sand distribution in the absence of vegetation, which we then used to validate the SDEVI. We conclude that the vulnerability index proposed in this work has identified the areas most susceptible to sand dune encroachment in Nouakchott, and the results coincide with the satellite images acquired in 2017 to monitor sand dune changes. While the SDEVI can assist local authorities and decision-makers in tackling sand encroachment with preventive and mitigation measures, the validation methodology can be applied to monitor sand dune evolution/stability over time and space in a cost-effective manner. We also propose the use of the B8/B2 ratio to differentiate between desert sand dunes in similar environments.

\section{Conclusions}

Sand encroachment is a major natural hazard that threatens roads, cultivated lands or settlements in Mauritania. In order to locate areas prone to suffering from sand dune encroachment in Nouakchott, we have developed the SDEVI vulnerability index that includes remote sensing variables and GIS data. To validate our model, we use active and passive satellite images to evaluate sand stability.

The findings indicate medium vulnerability values at Nouakchott, although they stress the greater vulnerability to sand encroachment in the eastern and north-eastern part of the city. S1 and S2 are seen to be suitable platforms to evaluate this index due to their high spatial resolution. Furthermore, they emerge as a highly valuable tool for monitoring the ongoing advance of sand dunes in near-real time. For optical imagery, the best approach to identify desert sand was the NIR (B8)/Blue (B2) ratio for the S2 satellite. We found that values greater than 2.51 can be identified as desert sand within our study area. Furthermore, the CCD technique quantified the degree of change in each pixel using SAR S1 images. We establish a 0.6 threshold for coherence values, with $>0.6$-pixel values being considered as stable over time.

Hence, the use of both sources of information to control sand dune evolution in arid areas is recommended. The SDEVI provides vulnerability maps to tackle sand encroachment and this information, coupled with optical and SAR monitoring techniques, can help local authorities and decision-makers to improve land management, urban planning, and to implement prevention and mitigation measures. 
Author Contributions: Conceptualization, D.G., J.L.C.; Methodology, D.G., P.S. and J.L.C.; Formal Analysis, D.G. and P.S.; Validation, P.S. and C.C.; Data Curation, D.G., J.S. and C.C. Writing-Original Draft Preparation, D.G. Writing-Review and Editing, D.G., P.S., J.L.C, J.S. and C.C.; Supervision, C.C., J.S., J.L.C.; Project Administration, J.S.

Funding: This research did not receive any specific grant from funding agencies in the public, commercial, or not-for-profit sectors.

Conflicts of Interest: All authors declare that they have no conflict of interest.

\section{References}

1. Berte, C.J. Fighting Sand Encroachment: Lessons from Mauritania; Food and Agriculture Organization of the United Nations (FAO): Rome, Italy, 2010. Available online: http://www.fao.org/docrep/012/i1488e/ i1488e00.pdf (accessed on 17 September 2018).

2. Giannini, A.; Biasutti, M.; Verstraete, M.M. A climate model-based review of drought in the Sahel: Desertification, the re-greening and climate change. Glob. Planet. Chang. 2008, 64, 119-128. [CrossRef]

3. Reynolds, J.F.; Stafford-Smith, D.M.; Lambin, E. Do humans cause deserts? An old problem through the lens of a new framework: The Dahlem desertification paradigm. In Proceedings of the 7th International Rangelands Congress, Durban, South Africa, 26 July-1 August 2003.

4. United Nations Convention to Combat Desertification (UNCCD). Preserving Our Common Ground: UNCCD 10 Years on; United Nations Convention to Combat Desertification: Bonn, Germany, 2004.

5. Holden, S.; Shiferaw, B. Land degradation, drought and food security in a less-favoured area in the Ethiopian highlands: A bio-economic model with market imperfections. Agric. Econ. 2004, 30, 31-49. [CrossRef]

6. Winslow, M.; Shapiro, B.I.; Thomas, R.; Shetty, S.V.R. Desertification, Drought, Poverty and Agriculture: Research Lessons and Opportunities; ICARDA: Aleppo, Syria, 2004; p. 52. Available online: http:/ /www.iwmi.cgiar.org/ assessment/files/Synthesis/Land\%20Degradation/DDPAARLO_text.pdf (accessed on 24 September 2018).

7. Pye, K.; Tsoar, H. Aeolian Sand and Sand Dunes; Springer: Berlin, Germany, 2008.

8. Kerr, R.C.; Nigra, J.O. Eolian sand control. AAPG Bull. 1952, 36, 1541-1573.

9. Thomas, R.J. Opportunities to reduce the vulnerability of dryland farmers in Central and West Asia and North Africa to climate change. Agric. Ecosyst. Environ. 2008, 126, 36-45. [CrossRef]

10. De Wit, M.; Stankiewicz, J. Changes in surface water supply across Africa with predicted climate change. Science 2006, 311, 1917-1921. [CrossRef] [PubMed]

11. Schlenker, W.; Lobell, D.B. Robust negative impacts of climate change on African agriculture. Environ. Res. Lett. 2010, 5, 014010. [CrossRef]

12. Tsoar, H. Sand dunes mobility and stability in relation to climate. Phys. A Stat. Mech. Its Appl. 2005, 357, 50-56. [CrossRef]

13. Effat, H.A.; Hegazy, M.N.; Haack, B. Mapping sand dunes risk related to their terrain characteristics using SRTM data and cartographic modeling. J. Land Use Sci. 2011, 6, 231-243. [CrossRef]

14. Khalaf, F.I.; Al-ajmi, D. Aeolian processes and sand encroachment problems in Kuwait. Geomorphology 1993, 6, 111-134. [CrossRef]

15. Durán, O.; Herrmann, H.J. Vegetation against dune mobility. Phys. Rev. Let. 2006, 97, 188001. [CrossRef] [PubMed]

16. Chenal, J.; Kaufmann, V. Nouakchott. Cities 2008, 25, 163-175. [CrossRef]

17. Lancaster, N.; Helm, P. A test of a climatic index of dune mobility using measurements from the southwestern United States. Earth Surf. Process. Landf. J. Br. Geomorphol. Res. Group 2000, 25, 197-207. [CrossRef]

18. Ahmady-Birgani, H.; McQueen, K.G.; Moeinaddini, M.; Naseri, H. Sand dune encroachment and desertification processes of the Rigboland Sand Sea, Central Iran. Sci. Rep. 2017, 7, 1523. [CrossRef] [PubMed]

19. Mihi, A.; Tarai, N.; Chenchouni, H. Can palm date plantations and oasification be used as a proxy to fight sustainably against desertification and sand encroachment in hot drylands? Ecol. Indic. 2017. [CrossRef]

20. Els, A.; Merlo, S.; Knight, J. Comparison of two Satellite Imaging Platforms for Evaluating Sand Dune Migration in the Ubari Sand Sea (Libyan Fazzan). Int. Arch. Photogramm. Remote Sens. Spat. Inf. Sci. 2015, 40, 1375. [CrossRef] 
21. Callot, Y.; Marticorena, B.; Bergametti, G. Geomorphologic approach for modelling the surface features of arid environments in a model of dust emissions: Application to the Sahara desert. Geodin. Acta 2000, 13, 245-270. [CrossRef]

22. Bodart, C.; Ozer, A. The use of SAR interferometric coherence images to study sandy desertification in southeast Niger: Preliminary results. In Proceedings of the Envisat Symposium, Montreux, Switzerland, 23-27 April 2007.

23. Tucker, C.J.; Dregne, H.E.; Newcomb, W.W. Expansion and contraction of the Sahara Desert from 1980 to 1990. Science 1991, 253, 299-300. [CrossRef] [PubMed]

24. Breed, C.S.; Grow, T. Dunes in sand seas observed by. US Geol. Surv. Prof. Pap. 1979, 1052, 253.

25. Al-dabi, H.; Koch, M.; Al-Sarawi, M.; El-Baz, F. Evolution of sand dune patterns in space and time in north-western Kuwait using Landsat images. J. Arid Environ. 1997, 36, 15-24. [CrossRef]

26. Hereher, M.E. Sand movement patterns in the Western Desert of Egypt: An environmental concern. Environ. Earth Sci. 2010, 59, 1119-1127. [CrossRef]

27. Hereher, M.E. Assessment of sand drift potential along the Nile Valley and Delta using climatic and satellite data. Appl. Geogr. 2014, 55, 39-47. [CrossRef]

28. Al-helal, A.B.; Al-Awadhi, J.M. Assessment of sand encroachment in Kuwait using GIS. Environ. Geol. 2006, 49, 960-967. [CrossRef]

29. Yao, Z.Y.; Wang, T.; Han, Z.W.; Zhang, W.M.; Zhao, A.G. Migration of sand dunes on the northern Alxa Plateau, Inner Mongolia, China. J. Arid Environ. 2007, 70, 80-93. [CrossRef]

30. Gaber, A.; Abdelkareem, M.; Abdelsadek, I.S.; Koch, M.; El-Baz, F. Using InSAR Coherence for Investigating the Interplay of Fluvial and Aeolian Features in Arid Lands: Implications for Groundwater Potential in Egypt. Remote Sens. 2018, 10, 832. [CrossRef]

31. Kwarteng, A.; Touzi, R.; Al-jassar, H. Utilization of satellite SAR imagery for mapping sand dunes in Kuwait. In Proceedings of the International Geoscience and Remote Sensing Symposium, Honolulu, HI, USA, 24-28 July 2000.

32. Chuvieco, E. Fundamentals of Satellite Remote Sensing; CRC Press: Boca Raton, FL, USA, 2009.

33. Henderson, F.M.; Lewis, A.J. Principles and Applications of Imaging Radar; Wiley India: Hoboken, NJ, USA, 2013.

34. Torres, R.; Snoeij, P.; Geudtner, D.; Bibby, D.; Davidson, M.; Attema, E.; Potin, P.; Rommen, B.; Floury, N.; Brown, M. GMES Sentinel-1 mission. Remote Sens. Environ. 2012, 120, 9-24. [CrossRef]

35. Moreira, A.; Prats-Iraola, P.; Younis, M.; Krieger, G.; Hajnsek, I.; Papathanassiou, K.P. A tutorial on synthetic aperture radar. IEEE Geosci. Remote Sens. Mag. 2013, 1, 6-43. [CrossRef]

36. Boulghobra, N. Sand encroachment in the Saharan Algeria; the not declared disaster-Case study: In-Salah region in the Tidikelt. Planet@Risk 2015, 3, 72-76.

37. National Oceanic and Atmospheric Administration (NOAA-NCDC). 2018. Available online: https: / / www. ncdc.noaa.gov/data-access/land-based-station-data (accessed on 10 August 2018).

38. Jensen, A.M.; Hajej, M.S. The Road of Hope: Control of moving sand dunes in Mauritania. Unasylva 2001, 52, 31-36.

39. Mainguet, M. Cordons longitudinaux (sandridges): Dunes allongées à ne plus confondre avec les sifs, autres dunes linéaires. Travaux de l'Institut de Géographie de Reims 1984, 59, 61-83. [CrossRef]

40. Mainguet, M. A dynamic classification of mobile dunes. Sand dune stabilization, shelterbelts and afforestation in dry zones. FAO Conserv. Guide 1985, 10, 17-25.

41. Jensen, A.M. Protection des Routes Contre l'ensablement en Mauritanie. Étude FAO 1993. Available online: http:/ /www.fao.org/docrep/004/y2795f/y2795f07.htm (accessed on 11 September 2018).

42. Bradley, D.C.; O’Sullivan, P.; Cosca, M.A.; Motts, H.; Horton, J.D.; Taylor, C.D.; Beaudoin, G.; Lee, G.K.; Ramezani, J.; Bradley, D.N. Synthesis of geological, structural, and geochronologic data (phase V, deliverable 53): Chapter A in Second projet de renforcement institutionnel du secteur minier de la République Islamique de Mauritanie (PRISM-II). US Geol. Surv. 2015. [CrossRef]

43. Arino, O.; Ramos Perez, J.J.; Kalogirou, V.; Bontemps, S.; Defourny, P.; Van Bogaert, E. Global Land Cover Map for 2009 (GlobCover 2009); PANGAEA—Data Publisher for Earth \& Environmental Science: Davis, CA, USA, 2012.

44. Hamdan, M.A.; Refaat, A.A.; Abdel Wahed, M. Morphologic characteristics and migration rate assessment of barchan dunes in the Southeastern Western Desert of Egypt. Geomorphology 2016, 257, 57-74. [CrossRef] 
45. Martínez-Graña, A.; Gómez, D.; Santos-Francés, F.; Bardají, T.; Goy, J.L.; Zazo, C. Analysis of Flood Risk Due to Sea Level Rise in the Menor Sea (Murcia, Spain). Sustainability 2018, 10, 780. [CrossRef]

46. GMAO.tavgM_3d_udt_Cp: MERRA 3D IAU Tendency, Wind Components, Monthly Mean V5.2.0.; GES DISC: Greenbelt, MD, USA, 2008.

47. Rodriguez, E.; Morris, C.S.; Belz, J.E. A global assessment of the SRTM performance. Photogramm. Eng. Remote Sen. 2006, 72, 249-260. [CrossRef]

48. Finkel, H.J. The barchans of southern Peru. J. Geol. 1959, 67, 614-647. [CrossRef]

49. Livingstone, I.; Warren, A. Aeolian Geomorphology: An Introduction; Longman: Harlow, UK, 1996.

50. Dong, Z.; Wang, X.; Chen, G. Monitoring sand dune advance in the Taklimakan Desert. Geomorphology 2000, 35, 219-231. [CrossRef]

51. García-Mora, M.R.; Gallego-Fernández, J.B.; Williams, A.T.; García-Novo, F. A coastal dune vulnerability classification. A case study of the SW Iberian Peninsula. J. Coast. Res. 2001, 17, 4.

52. Van Der Sande, C.J.; De Jong, S.M.; De Roo, A.P.J. A segmentation and classification approach of IKONOS-2 imagery for land cover mapping to assist flood risk and flood damage assessment. Int. J. Appl. Earth Obs. Geoinf. 2003, 4, 217-229. [CrossRef]

53. Yizhaq, H.; Ashkenazy, Y.; Tsoar, H. Sand dune dynamics and climate change: A modeling approach. J. Geophys. Res. Earth Surf. 2009, 114. [CrossRef]

54. Yao, S.X.; Zhao, C.C.; Zhang, T.H.; Liu, X.P. Response of the soil water content of mobile dunes to precipitation patterns in Inner Mongolia, northern China. J. Arid Environ. 2013, 97, 92-98. [CrossRef]

55. Dorigo, W.; Wagnera, W.; Albergelb, C.; Albrechtc, F.; Balsamod, G.; Broccae, L.; Chunga, D.; Ertlf, M.; Forkela, M.; Gruber, A.; et al. ESA CCI Soil Moisture for improved Earth system understanding: State-of-the art and future directions. Remote Sens. Environ. 2017, 203, 185-215. [CrossRef]

56. Liu, Y.Y.; Dorigo, W.A.; Parinussa, R.M.; de Jeu, R.A.; Wagner, W.; McCabe, M.F.; Van Dijk, A.I.J.M. Trend-preserving blending of passive and active microwave soil moisture retrievals. Remote Sens. Environ. 2012, 123, 280-297. [CrossRef]

57. Wagner, W.; Dorigo, W.; de Jeu, R.; Fernandez, D.; Benveniste, J.; Haas, E.; Ertl, M. Fusion of active and passive microwave observations to create an essential climate variable data record on soil moisture. ISPRS Ann Photogramm. Remote Sens. Spat. Inf. Sci. 2012, 7, 315-321.

58. Escorihuela, M.J.; Merlin, O.; Stefan, V.; Moyano, G.; Eweys, O.A.; Zribi, M.; Ghaout, S. SMOS based high resolution soil moisture estimates for Desert locust preventive management. Remote Sens. Appl. Soc. Environ. 2018, 11, 140-150. [CrossRef]

59. European Space Agency. Mission Sentinel 2, Overview. 2016. Available online: https://sentinel.esa.int/ web/sentinel/missions/sentinel-2 (accessed on 12 February 2018).

60. European Space Agency. Sentinel Application Platform. 2016. Available online: http://step.esa.int/main/ toolboxes/snap (accessed on 26 July 2018).

61. Louis, J.; Debaecker, V.; Pflug, B.; Main-Korn, M.; Bieniarz, J.; Mueller-Wilm, U.; Gascon, F. Sentinel-2 Sen2Cor: L2A Processor for Users. Living Planet Symp. 2016, 740, 91.

62. Hugenholtz, C.H.; Levin, N.; Barchyn, T.E.; Baddock, M.C. Remote sensing and spatial analysis of aeolian sand dunes: A review and outlook. Earth-Sci. Rev. 2012, 111, 319-334. [CrossRef]

63. Runnström, M.C. Rangeland development of the Mu Us Sandy Land in semiarid China: An analysis using Landsat and NOAA remote sensing data. Land Degrad. Dev. 2003, 14, 189-202. [CrossRef]

64. Bullard, J.E.; White, K. Quantifying iron oxide coatings on dune sands using spectrometric measurements: An example from the Simpson-Strzelecki Desert, Australia. J. Geophys. Res. Solid Earth 2002, 107, ECV 5-1-ECV 5-11. [CrossRef]

65. Leu, D.J. Visible and near-Infrared reflectance of beach sands: A study on the spectral reflectance/grain size relationship. Remote Sens. Environ. 1977, 6, 169-182. [CrossRef]

66. Sadiq, A.; Howari, F. Remote sensing and spectral characteristics of desert sand from Qatar Peninsula, Arabian/Persian Gulf. Remote Sens. 2009, 1, 915-933. [CrossRef]

67. Havivi, S.; Amir, D.; Schvartzman, I.; August, Y.; Maman, S.; Rotman, S.R.; Blumberg, D.G. Mapping dune dynamics by InSAR coherence. Earth Surf. Process. Landf. 2018, 43, 1229-1240. [CrossRef]

68. Liu, J.G.; Black, A.; Lee, H.; Hanaizumi, H.; Moore, J.M. Land surface change detection in a desert area in Algeria using multi-temporal ERS SAR coherence images. Int. J. Remote Sens. 2001, 22, 2463-2477. [CrossRef] 
69. Colesanti, C.; Ferretti, A.; Novali, F.; Prati, C.; Rocca, F. SAR monitoring of progressive and seasonal ground deformation using the permanent scatterers technique. IEEE Trans. Geosci. Remote Sens. 2003, 41, 1685-1701. [CrossRef]

70. Massonnet, D.; Feigl, K.L. Radar interferometry and its application to changes in the Earth's surface. Rev. Geophys. 1998, 36, 441-500. [CrossRef]

71. Veci, L. Sentinel-1 Toolbox TOPS Interferometry Tutorial. ESA, 2016. Available online: https://sentinel.esa. int/web/sentinel/toolboxes/sentinel-1/tutorials (accessed on 11 September 2018).

72. SNAP-ESA Sentinel Application Platform v6. 2018. Available online: http://step.esa.int/main/toolboxes/ snap/ (accessed on 5 April 2018).

73. Small, D.; Schubert, A. Guide to ASAR Geocoding; ESA-ESRIN Technical Note RSL-ASAR-GC-AD 1.01; ESA: Paris, France, 2008.

74. Srivastava, H.S.; Patel, P.; Navalgund, R.R. Application potentials of synthetic aperture radar interferometry for land-cover mapping and crop-height estimation. Curr. Sci. 2006, 91, 6.

75. Touzi, R.; Lopes, A.; Bruniquel, J.; Vachon, P.W. Coherence estimation for SAR imagery. IEEE Trans. Geosci. Remote Sens. 1999, 37, 135-149. [CrossRef]

76. Liu, Q.; Liu, G.; Huang, C.; Zhang, Y.; Guo, Y. Remotely sensed surface characteristics of three deserts in the Alxa Plateau, Inner Mongolia, China. In Proceedings of the Geoscience and Remote Sensing Symposium (IGARSS), Fort Worth, TX, USA, 23-28 July 2017; pp. 55-58.

77. Earth Resources Observation and Science (EROS) Center-US Geological Survey (EROS-USGS). 2016. Available online: https://eros.usgs.gov/westafrica/case-study/nouakchott-urbanization-gates-desert (accessed on 13 August 2018).

78. Drusch, M.; Del Bello, U.; Carlier, S.; Colin, O.; Fernandez, V.; Gascon, F.; Meygret, A. Sentinel-2: ESA's optical high-resolution mission for GMES operational services. Remote Sens. Environ. 2012, 120, $25-36$. [CrossRef]

79. Chang, C.W.; Laird, D.A.; Mausbach, M.J.; Hurburgh, C.R. Near-infrared reflectance spectroscopy-principal components regression analyses of soil properties. Soil Sci. Soc. Am. J. 2001, 65, 480-490. [CrossRef]

80. Blumberg, D.G. Remote sensing of desert dune forms by polarimetric synthetic aperture radar (SAR). Remote Sens. Environ. 1998, 65, 204-216. [CrossRef]

81. Khalil, R.Z. InSAR coherence-based land cover classification of Okara, Pakistan. Egypt. J. Remote Sens. Space Sci. 2017, 21, S23-S28. [CrossRef]

82. Martone, M.; Bräutigam, B.; Rizzoli, P.; Krieger, G. TanDEM-X performance over sandy areas. In Proceedings of the EUSAR 2014, 10th European Conference on Synthetic Aperture Radar, Berlin, Germany, 3-5 June 2014.

83. Marghany, M. DEM reconstruction of coastal geomorphology from DINSAR. In Proceedings of the Computational Science and Its Applications, Melbourne, Australia, 2-5 July 2018; pp. 435-446.

84. Blumberg, D.G.; Neta, T.; Margalit, N.; Lazar, M.; Freilikher, V. Mapping exposed and buried drainage systems using remote sensing in the Negev Desert, Israel. Geomorphology 2004, 61, 239-250. [CrossRef] 